\title{
The Internet of Things - the Nearest Future of Viticulture
}

Ekaterina Kudryashova ${ }^{1}$, Michele Casetti ${ }^{2}$

${ }^{1}$ Institute of Legislation and Comparative Law under the Government of Russian Federation, Moscow, Russia

${ }^{2}$ University of Bologna, Italy

\begin{abstract}
It is recognized that viticulture and wine sector in general successfully combines traditions and innovations. The Internet of Things technology has already found its way to the vineyards as a prospective innovation. The innovations in wine industry are discussed in the publications, however, IoT not so often falls within the focus.

In order to show the production and consumption trends in viticulture we rely mostly on the data accumulated by the International Organization of Vine and Wine. Some analytical materials of Food and Agriculture Organization of the United Nations were also relevant for this study. The information about implementation of Internet of Things is quite fragmentated by now and was collected from different sources.

At least two drivers of Internet of Things in viticulture could be mentioned. The first is the climate change and the need to respond to its challenges by wine growers. Technology helps to detect the changes and suggest the best and timely solutions. The second reason why the IoT has prospective in wine sector follows from the characteristics of wine and its consumption trends. There are quite a few strategic decisions to be taken by wine producer and consumers related to wine. These strategic decisions need to be based on a precise data accumulation and processing. The Internet of things is relevant for the decisions of storage, sales, ratings, and collectibles. The range of end-users of the data processing is wide enough in the wine sector.
\end{abstract}

The Internet of Things is already reality of viticulture and it has prospective to develop further. This paper argues that viticulture is a readily open for the IoT and there is a field for IoT implementation in there.

\section{Keywords}

Internet of Things, IoT, wine, consumption, viticulture, smart agriculture, internet of grape, smart vineyard, law and technology.

JEL Classification Q160, N50, L66, L86, E21

Kudryashova, E. and Casetti, M. (2021) "The Internet of Things - the Nearest Future of Viticulture", AGRIS on-line Papers in Economics and Informatics, Vol. 13, No. 2, pp. 79-86. ISSN 1804-1930. DOI 10.7160/aol.2021.130206.

\section{Introduction}

Recently the concept of "smart agriculture" became the core idea of the innovations in the contemporary agricultural sector (OECD-FAO, 2020). The vitiviniculture is among the first where new digital technologies are successfully implemented. The digitalization comes to the vineyards and makes them more efficient, more productive and improves control over the processing (OECD, 2019).

Quite an important part of the viticulture digitalization is the implementation of the Internet of Things (IoT) technologies. Collecting data from things then accumulating the data via internet, analyzing it and even suggesting the correct decision - that is the essence of the internet of things. The IoT in viticulture supports the decision making on irrigation, fertilization, harvesting etc. The new technology allows the optimal mapping of vineyards as well as quick reactions to the changing circumstances and ambient conditions. Technologies in general and the IoT in particular open the new opportunities for the winegrowers and become more and more popular. There is even a new term "internet of grape" sometimes used in the publications (Rossanez et al, 2018). 
Innovations and modern technologies related to the wine sector are popular topics of international academic research. There are already a few studies devoted just to the bibiliography in this field (Seccia, 2019, Glänzel and Veugelers, 2006 ). Comparative studies of innovations in wine sector of different countries constitute a bulk of publications (Cusmano et al., 2010).

The publications focusing on the wine sector usually characterize the viticulture and wine making as an industry where traditions and innovations constitute a successful combination or a synergy (Stupino et al., 2019; Vrontis et al., 2016).

In the studies on innovations management the contemporary innovations are usually classified into internal, external, and mixed (Schilling M. 2020, Shashkova and Kudryashova, 2020). This classification is successfully applied to the viticulture and wine sector (Vrontis et al., 2016). IoT in the wine sector was also in the focus of social sciences studies (Spadoni et al., 2019, Bencini et al., 2010).

However, the IoT technology in vitiviniculture did not attract much attention of academics. This paper is filling this gap referring to the already existing cases and showing the prospective of IoT implementation in viticulture. The purpose of this paper is to demonstrate the potential of IoT for the viticulture.

\section{Materials and methods}

Two important international organizations are dealing with the viticulture around the world and accumulate the data about the wine production, wine consumption and vitiviniculture. These two organizations are The Food and Agriculture Organization of the United Nations (FAO) and the International Organization of Wine and Vines (OIV).

The Food and Agriculture Organization was found as a specialized agency of the United Nations mainly focused on the food security. The FAO has 194 member states and works in more than 130 countries worldwide ${ }^{1}$. Usually, viticulture forms a part of agriculture. It was not the case in some countries. Due to the focus on the general issues of agriculture and food security the data of FAO refers to grape not dividing it to the table grape and wine grape. Therefore, not all the conclusions and data are relevant for this study.
More relevant information can be found in the data and documents of another international organization - the International Organization of Vine and Wine. OIV is an intergovernmental organization with a focus on vines, wine, wine-based beverages, table grapes, raisins and other vine-based products. By 2018 the OIV the representatives of 48 counties already took part in its work ${ }^{2}$.

In this research we shall rely mostly on the data of the OIV and on certain conclusions of FAO specifically referring to winemaking.

This research paper endeavors to present the viticulture as a field where IoT can be readily implemented and disseminate in the nearest future. The following hypotheses could be drafted for this research paper:

Hypothesis 1: There is a need for the IoT in viticulture. The drivers for IoT implementation in viticulture could be identified in the contemporary changing world;

Hypothesis 2: Due to the objective need for IoT in viticulture there should be an evidence for that and examples of successful applications. Based on these examples we can assert that there is a prospective for IoT implementation and market for this technology.

The combination of empirical and theoretical methods is employed in this research. The issue of this study shall be placed in a broader context. The first hypothesis requires to give a reason why the IoT is needed in the viticulture. Characteristics of wine and certain consumption trends are relevant for carrying out this task.

Design of this research required to find examples of the implemented technologies around the world. This task was successfully performed and the cases from different parts of the world are presented in this research. The aim of the paper is to collect and analyze the information about the IoT projects and show the drivers of the new technologies implementation in viticulture and agriculture. Most of the literature in the field do not focus specifically on the IoT in viticulture. This paper fills in this gap.

\section{Results and discussion}

\section{Driving factors for the IoT development in viticulture}

There are a few drivers for implementation of the IoT technologies in viticulture and the list

\footnotetext{
${ }^{1}$ http://www.fao.org/about/en/ (Accessed 12 May 2021)

${ }^{2}$ https://www.oiv.int/en/the-international-organisation-of-vine-and-wine/member-states-and-observers (Accessed 12 May 2021 )
} 
of them could be extensive and never closed. Some of these drivers are shared with other sectors of agriculture and others are specific for the viticulture. The list of factors includes both natural and social factors. In this research we focus on two factors which seemed to us the most important this time and relevant for IoT technologies.

The first factor to be mentioned here is the climate change. It is the natural factor relevant for agriculture in general, but still having peculiarities specific for viticulture.

Only zones roughly between the $30^{\text {th }}$ and $50^{\text {th }}$ latitudes are suitable for wine growing. These zones were quite stable for a long time and traditions were established within these territories of viticulture. Besides the link to territory within the general limits of winegrowing area viticulture is strongly tied to the place and its characteristics which is well expressed in the concept of terroir - unique interplay of natural (soil, climate etc.) and cultural (traditions, wine makers practices etc.) factors inherent to a limited area (Vaudour, 2002).

Many agricultural products are sensitive to the change of climatic factors (OECDFAO, 2020). However, wine is special because of a limited zone of quality winemaking and the concept of terroir. The climate change moves limits of this traditional zones and force wine makers to look for new solutions. At the same time the historically established terroirs are distorted(Tomasi, 2013).

Improving technological support for decisionmaking related to the vineyards helps to find solutions of how to keep the historical terroir. The IoT accumulating and allowing to analyze the data of the vineyards precisely shows the climate changes and allows timely decision making on the wine variety and the farm management.

The second driver of the technological changes in viticulture is the nature of wine as a product. The quality of wine and the traceability of its production are very important for consumers (Bencini et al., 2010; Casetti and Kudryashova, 2021)

Demand for wine is quite steady as well as production quantities according to the data of OIV collected since 1995 (Figure 1).

According to OIV the vineyard surface area and consumption of wine is stable or grows poorly (OIV, 2019)

However, the market is very competitive (OIV, 2019), and consumers are obsessed by quality of wine and those factors which impact the price (processing, traceability, fame of vineyards etc.). Innovations has been identified as the key success factor for the increasingly competitive wine industry (Hira and Swartz, 2014). The prices of wine unlike the other agricultural products varies from year to year (Pitt, 2017). The wine prices can change enormously from year depending on the weather conditions. Other peculiarity related to the variation of price is that the weather conditions are relevant for the longevity of wines. The storability is an important quality of fine wines and the value of wine is preserved with years or even grow dramatically. The variation of prices

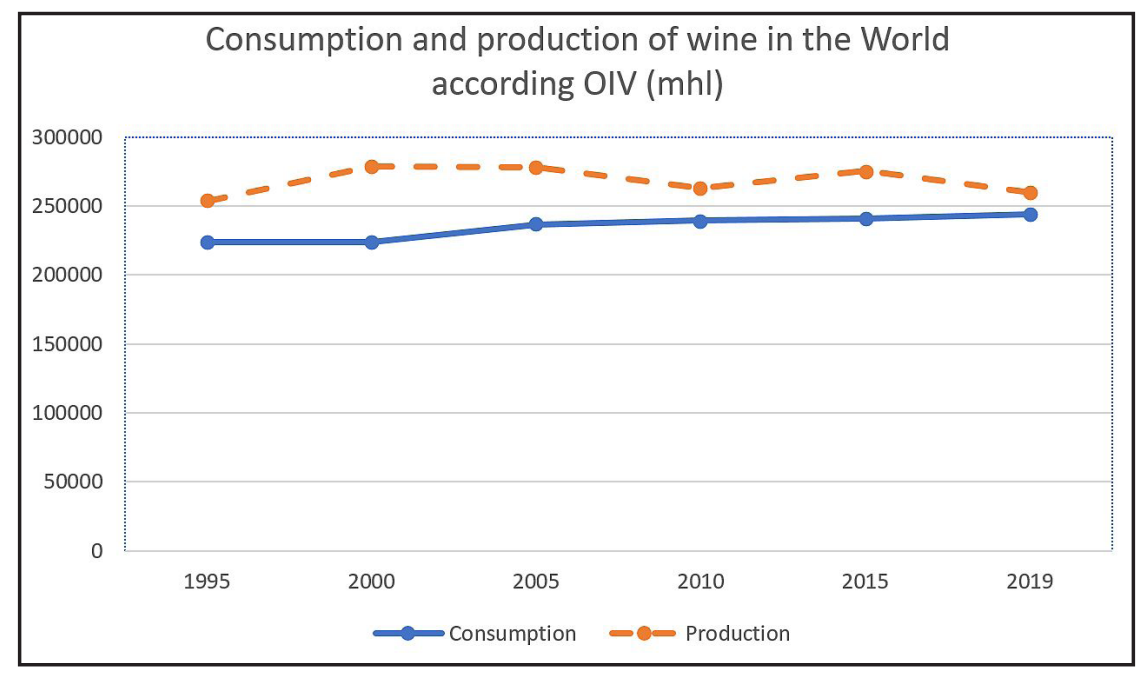

Source: Based on the data of OIV https:/www.oiv.int/en/statistiques/recherche

Figure 1: Consumption and production of wine in the world according to OIV ( $\mathrm{mhl})$. 
forces the wine makers to take both strategical decisions requiring massive of data and take more interim decisions.

Wine sector in general is quite steady, but recently there are some changes in consumption patterns. Globalization and regional integration processes has brought the culture of wine consumption to the countries where it was not a traditional earlier.

The OIV declares that wine is being consumed more and more in the countries with a large, young population. The data of OIV shows that the consumption of wine in Europe where it is traditional is slightly decreased meanwhile consumption of wine in Asia slightly increased (Figure 2).

Besides the general trends in consumption patterns the mass tourism comes into play. The international hotel business and the tourist flow from western world expanded the demand for wine in the regions where wine was not consumed due to traditional, religious, and cultural factors.

\section{Examples of IoT implementation in viticulture}

The IoT technology falls within the external or mixed innovations. It is not an invention of vineyards and wine makers. IoT is usually developed by the computer and technology industry. However, development of IoT for viticulture is not possible without participation of wine industry. The knowledge of viticulture resides in the vineyards. There are already the pilot projects of implementations of IoT in the specific vineyards as well as the projects

${ }^{3}$ Tracovino: In vino IoT https://www.wespeakiot.com/tracovino-in-vino-iot/

${ }^{4}$ Ericsson Connected Vineyards https://www.ericsson.com/4a21f3/assets/local/news/2015/12/iot-connected-vineyards.pdf

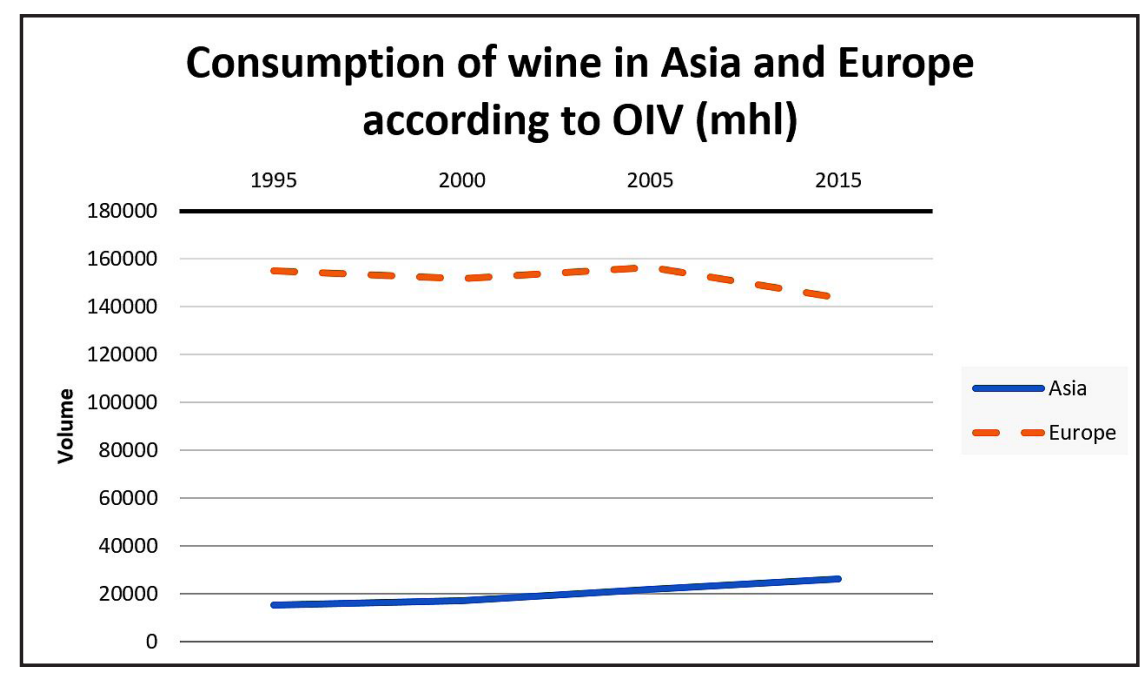

Source: Based on the data of OIV https://www.oiv.int/en/statistiques/recherche

Table 2: Consumption of wine in Asia and Europe according to OIV (the data is available only up to 2016). realized in cooperation with wine science, winemakers and the technological company.

Here we demonstrate the examples of implementation of IoT in viticulture as an evidence that the IoT is not a distant future in this sector. There are already a few companies involved in research and development of the IoT technologies intended for wineries.

The Tracovino is a project which is already commercialized and available for sale on the market. The project carried out by Ericsson, Intel, MyOmega System Technologies and Telenor Connexion. Each company provided a certain component for the project. This project was implemented on four wineries in Germany. The Tracovino system put together platform, sensors, networks and smartphones. Various information about the soil $\mathrm{PH}$, moisture, nutrient components, information about the climate and weather conditions (temperature, humidity, solar radiation, enlightment etc.). The system is energy efficient and solar-powered. As a product for winemakers Tracovino is a package of sensors, controllers, services ${ }^{3}$. By 2015 a few winemakers were already connected to Tracovino: Knebel, Clemens, Franzen. Haart ${ }^{4}$.

The EU Integrated project "GoodFood" should be mentioned here. Although it is nearly, but not exactly IoT project according to the opinion of its authors. In this project the "Ambient Intelligence" technologies was deployed in a few pilot sites. Ambient Intelligence (AmI) was designed to get 
simple data from smart sensors, fusing and mining data allowing the user to have a reliable and detailed information of changes in the environment in order to let the user control the site and make decisions wherever in the world. AmI is the concept very close to IoT but the AmI is not a self-controlled system. A few of the pilot sites were organized in Italy. One of the pilot sites was deployed in 2005 in the Montepaldi farm, Chianty Tuscany Italy. This pilot site is owned by the University of Florence. Another was deployed in 2007 in the Chanti Classico area, monitoring the variations in "terroir". The AMI technology in the GoodFood project proved to be reliable and able to provide detailed data representation to the final users. (Bencini et al., 2010)

There is an example of pilot IoT project in the viticulture coming from the United States. Salt Creek Vineyard based in Massachusetts implemented the IoT for detecting weather parameters and soil parameters. The Salt Creek Vineyard manage several fields with completely different microclimates therefore the wineries must be cared for differently. The project relies on the technologies and equipment provided by Dell and INEX IoT Impact Labs with their partners 5 .

Recently a very advanced and sophisticated digital technology product was announced in Australia. And this project is the outcome of the joint efforts of different sectors of economy and government. The Australian project VitiVisor is a one of the most advanced in terms of digitalization of vitiviniculture. The VitiVisor platform is designed to collect data from the vineyards by means of sensors and cameras generating the massive of data (Savage, 2020). The collected data is stored and analyzed by and artificial intelligence. Based on the analysis the VitiVisor offers advice on the irrigation, pruning, fertilizers, fungicide application etc. The IoT helps to aggregate together different technologies and scientific knowledge: the engineering, agriculture economics, water technologies, artificial intelligence, robotics, remote sensing The VitiVisor is a digital platform developed by the University of Adelaide in cooperation with the non-commercial organizations from the wine sector. The project is supported by the wine industry and regions of Australia. The platform shall be open for access to all the winegrowers in Australia. This kind of projects became possible only due to teamwork of research (academic), policy (government) and industry and synergia of their intentions and interests (Hira and Aylward, 2013).

\section{Discussion}

"Datafication and digitization" have recently increased the volume and coverage of agricultural data and mentioned cases demonstrate it. Combined with the progress in communication development and processing capacity these data technology developments pushed the farm management to a new level. Large streams of data and increase of the analyzing capacity enabled to establish dependencies and make predictions informing and serving the day to day decision-making process. Still the contemporary data processing technologies have not been used to its full potential to date (OECD, 2019, Shashkova and Verlaine, 2020). IoT is one of the most relevant contemporary technologies for agriculture and in particular viticulture.

At least two drivers for the implementation of IoT in viticulture could be mentioned. The possible climate change is one of them. The zone for production of wine is quite limited therefore the viticulture is very sensitive to the moves of these limits. IoT technology collecting data helps to preserve the historical zone serving the decision taking. The IoT allows to understand better the traditional terroirs collecting more precise data about the microclimate (Tomasi et al., 2013). In the future if the climate will really change it will help to preserve the historical terroirs.

The IoT helps not only to take better decisions on the vineyards within the traditional winegrowing zones, IoT technology allow to make the attempts to broaden the traditional wine making zones. More data and data processing technologies are needed for setting vineyards in a non-traditional location. The precise data on the microclimate conditions allows to find spaces eligible for wine growing outside the traditional wine regions and closer to the main tourism directions. Good illustration here is the concept of New Latitude Wines. New Latitude wines are produced of wine grape grown outside the traditional wine growing band. For example, the experimental wineries developed by the Chinese wine company Changyu in Thailand produces red and white table wines well under 18 degree of north latitude. In order to carry out this project sensors were placed in different arears of Thailand to find territorial spots eligible for vineyards in Thailand (Robinson, 2015). The touristic infrastructure needs much wine more convenient and cheap comparing to the imported wines.

Another driver for IoT implementation is the special interest to the quality of wine and traceability of its

\footnotetext{
${ }^{5}$ https://www.iotworldtoday.com/2016/12/07/11-innovative-iot-use-cases/
} 
production. Special feature of wine is its storability and the price variation depending on the weather conditions in a specific year. Due to the specific characteristics of wine the wine producer has to take more strategic decisions than other farmers. There are certain concepts of special years which are better than others. For example, the wine maker decides to keep the wine for more years - like the colheita port wine. The winemaker decides on the longevity of wine. Therefore, there is a demand for more precise and extensive data.

Wine is a special product in terms of the information required by consumer as well. Even the labelling of wine is thoroughly regulated and contain the information about the country, region, estate or property where the grape for the specific wine comes from. And consumer wants to know even more about wine: how they store and process it, and how they use it. (Pitt L. 2017) Various ratings, opinions of experts etc. are surrounding wine. The stakeholders around wine industry like auctioneers, sommeliers, restaurants, wine collectors, wine experts and reviewers etc. become the end-users of the information and predictions on the basis of the IoT. Not only the winemakers need it as precise as possible.

For the viticulture IoT is the contemporary reality rather than the future. There are already commercial projects in this field and we have demonstrated a few of them coming from different parts of the world. The examples show that IoT is already in use for a few years and there are no signs that the participants want to stop them.

The experts of the FAO noted that the quality of wine is not good enough in many territories due to the lack of awareness of the modern viticulture practices (FAO UN, 2010) The same could be said about the IoT technology in viticulture. It was not so easy to bring together these examples. To certain extent even this article contributes to the modernization of viticulture giving the information about the IoT in viticulture.

\section{Conclusion}

The viticulture is the sector of agriculture where the implementation of IoT is mostly expected. There are two factors which can facilitate the implementation. First is the climate change which has particular impact on viticulture. Second factor refer to specific characteristics of wine. These factors in the future relevant for proper assessment of the market for IoT technologies in viticulture and further prospects of growth.

\section{Corresponding authors}

Ekaterina Kudryashova, Doctor of Law.

Institute of legislation and comparative law under the Government of Russian Federation, 117218, B. Cheremushkinskaya, 34, Moscow, Russia

E-mail: ev_kudryashova@inbox.ru

\section{References}

[1] Bencini, L., Collodi, G., Di Palma, D., Manes, A. and Manes, G. (2010) "A Real Implementation and Deployment for Wine Production Management Based on Wireless Sensor Network Technology", In: Giusto, D., Iera, A., Morabito, G., Atzori ,L. (eds)"The Internet of Things", Springer, New York, NY, pp. 339-348. E-ISBN 978-1-4419-1674-7, ISBN 978-1-4419-1673-0. DOI 10.1007/978-1-4419-1674-7_33.

[2] Kudryashova, E. and Casetti, M. (2021) "Digital technologies in wine sector: Russian legislator preferences", IOP Conference Series: Earth and Environment Science699, Vol. 699, Development of the agro-industrial complex in the context of robotization and digitalization of production in Russia and abroad 15-16 October 2020, Yekaterinburg City, Russian Federation. DOI 10.1088/1755-1315/699/1/012002.

[3] Cusmano, L., Morrison, A. and Rabellotti, R. (2010) "Catching up Trajectories in the Wine Sector: A Comparative Study”, SSRN Electronic Journal, Vol. 38, No. 11, pp. 1588-1602. ISSN 0305-750X. DOI 10.1016/j.worlddev.2010.05.002.

[4] FAO UN (2010) "Agribusiness Handbook: Grapes Wine", EBRD, Food and agriculture organization of the UN. 
[5] Glänzel, W. and Veugelers, R. (2006) "Science for wine: a bibliometric assessment of wine and grape research for wine-producing and consuming countries", American Journal of Enology and Viticulture, Vol. 57, pp. 23-32. ISSN 0002-9254.

[6] Hira, A. and Aylward, D. (2013) "Australia as a Triple Helix exemplar: built upon a foundation of resource and institutional coordination and strategic consensus", Prometheus: Critical Studies in Innovation, Vol. 31, No. 4, pp. 399-417. E-ISSN 1470-1030, ISSN 0810-9028. DOI 10.1080/08109028.2014.933599.

[7] Hira, A. and Swartz, T. (2014) "What makes Napa Napa? The roots of success in the wine industry", Wine Economics and Policy, Vol. 3, No.1, pp. 37-53. ISSN 2212-9774. DOI 10.1016/j.wep.2014.02.001.

[8] Mohan, M. D. (2016) "Out with the old, in with the new: An analysis of economic trends beyond new world wine innovation", Suffolk Transnational Law Review, Vol. 39, No. 1, pp. 81-106. ISSN 0886-2648.

[9] OECD (2019) "Digital Opportunities for Better Agricultural Policies", OECD Publishing, Paris. [Online]. Available: https://www.oecd.org/publications/digital-opportunities-for-better-agriculturalpolicies-571a0812-en.htm [Accessed: 15 Apr. 2020].

[10] OECD-FAO (2020) "OECD-FAO Agricultural Outlook 2020-2029", FAO, Rome/OECD Publishing, Paris.

[11] OIV (2019) "State of the World vitivinicultural sector in 2019", Report. [Online]. Available: http://www.oiv.int/public/medias/7298/oiv-state-of-the-vitivinicultural-sector-in-2019.pdf [Accessed: 1 March 2021).

[12] Piña-Rey, A., González-Fernández, E., Fernández-González, M., Lorenzo, M. N. and Rodríguez-Rajo, F. J. (2020) "Climate Change Impacts Assessment on Wine-Growing Bioclimatic Transition Areas", Agriculture, Vol. 10, No. 12, pp. 605-626. ISSN 2077-0472. DOI 10.3390/agriculture10120605.

[13] Pitt, L. (2017) "Ten reasons why wine is a magical marketing product", Journal of Wine Research, Vol. 28, No. 4, pp. 255-258. E-ISSN 1469-9672, ISSN 0957-1264. DOI 10.1080/09571264.2017.1395386.

[14] Rossanez, A., Gonçales, R. B., Borin, J. F., (2018) "Internet of Grapes (IoG): Uma Solução para Cultivo de Uvas Baseada na Internet das Coisas", Report No. IC-18-21. [Online]. Available: https://www.ic.unicamp.br/ reltech/2018/18-21.pdf [Accessed: 1 May 2021).

[15] Robinson, M. (2015) "New Latitude Wines". [Online] Available: https://learn.winecoolerdirect.com/ new-latitude-wines/ [Accessed: 1 March 2021].

[16] Savage, C. (2020) "Technology to transform vineyard management". Official web site of the University of Adelaide. [Online]. Available: https://www.adelaide.edu.au/newsroom/news/ list/2020/01/15/technology-to-transform-vineyard-management [Accessed: 1 March 2021).

[17] Stupino, M., Giacosa, E. and Pollifroni, M. (2019) "6 -Tradition and Innovation Within the Wine Sector: How a Within Combination Could Increase the Company's Competitive Advantage, In: Processing and Sustainability of Beverages, Vol. 2: The Science of Beverages, pp. 185-204. ISBN 978-0-12-815259-1. DOI 10.1016/B978-0-12-815259-1.00006-9.

[18] Seccia, A. (2015) "Diffusion of innovation in the wine industry: a review of the literature". [Online]. Available: https://www.researchgate.net/publication/281441838_Diffusion_of_innovation_in_the_ wine_industry_a_review_of_the_literature [Accessed 15 Oct. 2020].

[19] Shashkova, A. and Verlaine, M. (2020) "12. Change of tax policy model as a base for innovation development while transferring from the pre-industrial to the Industrial society", In: Kovalchuk, J. (ed) "Post-industrial Society. The Choice Between Innovation and Tradition". pp. 137-147, Springer International Publishing. E-ISBN 978-3-030-59739-9, ISBN 978-3-030-59738-2. DOI 10.1007/978-3-030-59739_9_12. 
[20] Shashkova, A. and Kudryashova, E. (2020) "Tax incentives issue for innovations in sustainable energy within the BRICS strategic partnership framework", E3S Web Conferences, Sustainable Energy Systems: Innovative Perspectives (SES-2020), Vol. 220, 01007 (2020). DOI 10.1051/e3sconf/202022001007.

[21] Schilling, M. (2020 ) "Strategic Management of Technological Innovation", $6^{\text {th }}$ ed., McGraw-Hill Education. NY. ISBN10 1260087956, ISBN13 9781260087956.

[22] Spadoni, R., Nanetti, M., Bondanese, A. and Rivaroli, S. (2019) "Innovative solutions for the wine sector: the role of startups", Wine Economics and Policy. Vol. 8, No. 2, pp. 165-170. ISSN 2212-9774. DOI 10.1016/j.wep.2019.08.001.

[23] Trendov, N. M., Varas, S. and Zeng, M. (2019) "Digital technologies in agriculture and rural areas - Status report", Briefing Paper. Rome. [Online]. Available: http://www.fao.org/3/ca4887en/ ca4887en.pdf. [Accessed 1 Dec. 2020].

[24] Tomasi, D., Gaiotti, V. and Jones, V. (2013) "Using Geospatial technologies to better understand terroir", In: "The Power of the Terroir: the Case Study of Prosecco Wine". Springer, Basel, pp. 215-234. E-ISBN 978-3-0348-0628-2, ISBN 978-3-0348-0627-5. DOI 10.1007/978-3-0348-0628-2_12.

[25] Vaudour, E. (2002) "The quality of grapes and wine in relation to geography: notions of terroir at various scales", Journal of Wine Research, Vol. 13, pp. 117-141. E-ISSN 1469-9672, ISSN 0957-1264. DOI 10.1080/0957126022000017981.

[26] Vrontis, D., Bresciani, S. and Giacosa, E. (2016) "Tradition and innovation in Italian wine family businesses”, British Food Journal, Vol. 118, No. 8, pp. 1883-1897. ISSN 0007-070X. DOI 10.1108/BFJ-05-2016-0192. 